\title{
UTENSILIOS DE COCINA: UN ANÁLISIS COMPONENCIAL
}

\author{
Annette Calvo Shadid
}

\begin{abstract}
RESUMEN
El siguiente trabajo presenta una descripción de lexemas referidos a los utensilios de cocina de operación manual, no eléctricos, activos y que tienen mango, y una definición de ellos basada en rasgos distntivos y en relaciones de sentido. Para esto, se utilizará la metodología denominada análisis componencial.
\end{abstract}

\begin{abstract}
The following is a description of lexemes related to non-electric, manual cooking utensils without a handle, as well as a definition based on distinctive features and meaning relationships. The study was carried out following the componential analysis methodology.
\end{abstract}

\section{Introducción}

Este trabajo presenta la descripción de un conjunto de lexemas referidos a los utensilios de cocina de operación manual, no eléctricos, activos y que tienen mango.

Se trabajará con la metodología denominada análisis componencial, para elaborar una definición basada en los rasgos distintivos que presentan estos lexemas y sus relaciones de sentido.

Los componentes se establecerán de acuerdo con cuatro variables que tienen que ver con la forma, tamaño, material y finalidad de dichos utensilios.

Para la definición, se tomará en cuenta no todo el instrumento, sino únicamente la parte extrema opuesta al mango, que es la que opera en la elaboración de los alimentos. El mango es sólo un componente diferenciador, que permite oponer estos utensilios a otros que no lo tienen.

El trabajo se divide básicamente en cinco partes: la primera es el marco teórico, en el cual se plantea en qué consiste al análisis componencial, y algunas cuestiones referentes a la noción del significado y del campo léxico. Las partes segunda y tercera se referirán a la definición de los rasgos semánticos que serán pertinentes en este análisis. En la cuarta parte se realizará la definición componencial de los lexemas, y en la quinta, se expondrán las conclusiones generales de la investigación. 


\subsection{Metodología}

Se trabajará con un corpus de 30 lexemas.

Para realizar el análisis, se trabajó con ocho informantes, hombres y mujeres, los cuales viven en el Área Metropolitana. Todos ellos son mayores de 21 años y poseen un alto nivel de instrucción (universitarios).

Se les pidió a los informantes que definieran cada uno de los lexemas de acuerdo con la finalidad, forma, tamaño y material que posee cada uno de ellos.

Además, se les preguntaron las razones por las cuales ellos creían que se habían seleccionado estos instrumentos y no otros; en otras palabras, se les pidió responder qué tenían en común estos utensilios, que los diferenciaba de otros que también se usan para cocinar.

De sus respuestas se tomaron, entonces, algunos de los rasgos que tienen en común estos lexemas, y los rasgos adicionales que se exponen en el desarrollo de este trabajo.

\section{Marco teórico}

El análisis componencial consiste, de acuerdo con Lyons (1981:82), "en la descomposición del sentido de un lexema en sus elementos constituyentes". Esto indica que, en el análisis del significado, es posible describir la estructura del vocabulario por medio de "componentes" semánticos (cfr. Bierwisch 1970: 180, Lyons 1970: 175, Lehrer 1974: 46) que se unen por "constantes lógicas" (cfr. Bierwisch 1970: 180) para conformar el significado de un lexema. Las constantes lógicas son, para Bierwisch, las propiedades y relaciones semánticas de los elementos léxicos. En términos de Lyons, estas son las relaciones de sentido que se dan entre componentes.

Por tanto, la definición de cada elemento del vocabulario de una lengua se da con base en las posibilidades combinatorias de dichos componentes.

Los diferentes elementos léxicos pueden tener tanto rasgos semánticos comunes, como rasgos diferentes que los oponen.

Por ejemplo, los lexemas hombre y mujer tienen en común los rasgos animado y humano; pero se oponen por el rasgo sexo. El primer término tiene el componente masculino (o -femenino), y el segundo tiene el componente femenino (o -masculino).

Es importante tener en cuenta, como lo manifiesta Lyons (1981: 90), que el análisis componencial está "considerado no como una técnica para la representación de todos y cada uno de los significados de los lexemas, sino como una manera de formalizar aquella parte de su significado prototípico o focal que comparte con otros lexemas".

En este sentido, la noción de prototipo es muy útil en el análisis del significado, debido a que con él se trabaja en la descripción más típica del lexema.

Hudson (1981: 89) le da bastante crédito a esta alternativa porque "permite la clase de flexibilidad creativa en la aplicación de conceptos con los que nos encontramos en la vida real; en otras palabras: predice que los límites entre los conceptos serán difusos, como de hecho lo son".

Del mismo modo, Lyons (1981: 77-9), al referirse al significado, dice que en muchos casos éste es "indeterminado y borroso". El hecho de que podamos comunicarnos adecuadamente unos con otros lo atribuye al hecho de que "normalmente no operamos con las zonas 
borrosas e indeterminadas del significado de las palabras". Esto indica que en la comunicación operamos con "prototipos o estereotipos".

Para Lyons, los prototipos son, precisamente, las zonas menos difusas o "focales" del significado, en oposición a las zonas más difusas, indeterminadas o "no focales", que serían "periféricas".

Al trabajar en el campo del significado, se hace necesario especificar el aspecto de éste que se va a tratar.

Entre varios tipos de significado lingüístico que hay, se utilizará aquí el de significado léxico, qué es el de las palabras o el de los lexemas (cfr. Jara 1986: 10).

El significado de los lexemas tiene dos enfoques: la denotación y el sentido (cfr. Lyons 1981: 64).

Para Lyons (1981: 66), la denotación "es una relación que se establece primaria o básicamente entre expresiones y entidades físicas de la realidad".

El sentido es definido por Lyons (1981: 65) como "el conjunto de relaciones de sentido que se mantienen entre dicha expresión y otra cualquiera". Luego señala que "el sentido es un resultado de las relaciones que se establecen entre expresiones lingüísticas".

Aquí se va a tratar el significado en el aspecto de las relaciones de sentido que se dan entre los lexemas.

Un aspecto importante en este trabajo, que tiene que ver con la denotación y el sentido, es la aplicación de expresiones léxicamente compuestas (cfr. Lyons 1981:66). Estas son frases que funcionan como una sola unidad léxica, ya que el objeto al cual se refieren no se puede denotar con una expresión más básica. Las frases lexemáticas usadas aquí son bastante familiares, y sus términos se conocen muy bien en el uso cotidiano. Por ejemplo, cuchillo de pan, cucharón sopero, cuchara de madera, cucharón para espagueti, cucharón perforado, taza y cucharas de medida, batidor de alambre, cortador de queso y punzón para repostería.

En forma paralela a lo que Lyons considera como denotación y sentido, Coseriu (1977: 130-1) define la relación entre lo que se ha llamado "designación" y "significación" de la siguiente manera:

Las relaciones de 'significación' son las relaciones entre los significados de los signos lingüísticos (a); las relaciones de 'designación' son las relaciones entre los signos lingüísticos y los 'objetos' (la 'realidad' a la que se refieren y a la que 'representan' en el discurso) (b):

(b)

(a)

Significante
Significado
Significado
Significante

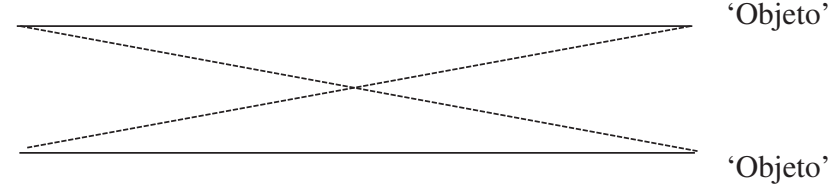

Con base en diversos autores, Geckeler (1976: 92-6) realiza una exposición acerca de estas relaciones de significado, para concluir que al estudiar las estructuras lexemáticas "tenemos que atender, ante todo, a las relaciones significativas, a las que llegamos, en la investigación práctica, a través de las relaciones designativas".

En el presente trabajo se utilizará la notación de sentido, tal y como ha sido expuesta por Lyons. 
De acuerdo con su formulación (Lyons 1981: 96), "las relaciones de sentido son de dos tipos: sustitutivas y combinatorias (o, en términos saussureanos (...), paradigmáticas y sintagmáticas)".

Aquí interesan las relaciones sustitutivas de sentido, las cuales se establecen entre miembros de la misma categoría conmutables entre sí.

Entre las relaciones sustitutivas de sentido, hay algunas de semejanza o afinidad y otras de diferenciación u oposición (cfr. Jara 1986: 11). Para los fines de este trabajo se indican las siguientes (cfr. Lyons 1981:49-61):

Relaciones de semejanza:

Sinonimia: relación entre las expresiones que tienen diferente forma pero igual significado. Hay sinonimia parcial y absoluta, y Lyons (1981-56) distingue la sinonimia parcial de la cuasisinonimia.

Homonimia: relación entre las expresiones que coinciden en cuanto a forma, pero se diferencian por su significado.

Polisemia: significado múltiple de un solo lexema.

Para Lyons (1981:51), la diferencia entre homonimia y polisemia radica en que en la homonimia, la relación se da entre dos o más lexemas distintos, mientras que la polisemia es una propiedad de un único lexema.

Hiponimia: relación entre un significado específico que se incluye en otro significado más general. Existe también una relación de co-hiponimia cuando dos o más lexemas se incluyen dentro de otro lexema supraordinado (cfr. Jara 1981: 11).

Relaciones de oposición:

Antonimia: relación entre dos lexemas extremos que se oponen, pero su oposición es graduable.

Complementariedad: relación de negación absoluta entre lexemas que se oponen completamente, sin que haya, por lo tanto, una oposición gradual.

Como se puede observar, las relaciones de sentido son las que se dan entre lexemas.

La existencia de estas relaciones de sentido entre los lexemas, es lo que permite estructurar lo que se ha denominado campo léxico.

Antes de entrar en la definición del campo léxico, es importante clarificar el concepto de estructuras paradigmáticas.

Según Coseriu (1977: 170), las estructuras paradigmáticas en el léxico son "estructuras constituidas por unidades léxicas que se encuentran en oposición en el eje de la selección".

De acuerdo con esto, un campo léxico viene a ser (Coseriu 1977: 170) "una estructura paradigmática constituida por unidades léxicas que se reparten una zona de significación común y que se encuentran en oposición inmediata las unas con las otras".

El campo léxico, al ser un sistema análogo al de las consonantes o vocales en fonología, es analizable en rasgos distintivos (cfr. Coseriu 1977: 171). 
De este modo, Coseriu define el lexema como una unidad de contenido léxico expresada en el sistema lingüístico. léxico.

El archilexema es una unidad semántica que equivale al contenido de todo un campo

Los rasgos distintivos que constituyen los lexemas pueden llamarse semas.

Estas definiciones de Coseriu pertenecen a la corriente de los semanticistas europeos. En este trabajo se utilizarán, más bien, los conceptos de rasgo y componente, tal y como fueron definidos por Lyons (1977:323). El término rasgo corresponde al de variable. Los rasgos o variables son elementos que tienen diferentes realizaciones. Estas realizaciones son definidas por Lyons como componentes o valores. Por ejemplo, en este estudio, la variable finalidad presenta doce componentes o valores; utensilios cortantes, aplastantes, triturantes, punzantes, etc.

Por otra parte, Coseriu ha realizado un aporte importante al introducir el concepto de oposición en el campo de la lexemática, basándose en los tipos de oposiciones desarrollados por la Escuela de Praga para la fonología (cfr. Geckeler 1974:301).

Coseriu toma las oposiciones fonológicas de Trubetzkoy e introduce en la teoría de los campos léxicos lo que llama "tipos formales de oposiciones" (Coseriu 1977:221-2). Estas son:

Oposiciones privativas: aquellas cuyos miembros están en una oposición x / no x. Por lo general, son constituidos por dos términos, de los cuales uno es la negación del otro.

Oposiciones graduales: aquellas cuyos miembros tienen distintos grados de la misma propiedad.

Oposiciones equipolentes: aquellas cuyos miembros tienen el mismo estatus; no poseen ni graduabilidad ni polaridad.

En lo que concierne a este trabajo, el concepto de oposición equipolente es el más significativo. Con este tipo de oposición se da lo que Coseriu (1977:222-3) llama "campos seriales":

Los campos seriales pueden ser ordinales o no ordinales. En los campos ordinales, las oposiciones son de índole 'relacional'; en los no ordinales, de índole 'sustantiva'. Los campos ordinales son series cerradas y los lexemas están ordenados en ellos en un orden fijo, lo cual, por otra parte, los determina como tales, ya que por lo demás, (si se quita lo que pertenece a los archilexemas) son términos semánticos vacíos. Los campos no ordinales son series no ordenadas y al mismo tiempo, abiertas: se les puede añadir indefinidamente nuevos lexemas.

Ya se ha señalado que los diferentes lexemas en un campo léxico se oponen por medio de rasgos distintivos mínimos. Por tanto, en este trabajo se utiliza la notación \pm para establecer dichas oposiciones, tal y como se ha aplicado en numerosos estudios de análisis componencial (cfr. Lyons 1977: 322-5, Lehrer 1974: 59 y ss., Margery 1984: 154).

El operador + (positivo) denota la presencia del componente en el lexema, y el rasgo - (negativo) denota la ausencia de tal componente.

El operador \pm indica que el componente es facultativo; el lexema puede tener el componente, pero este no es obligatorio.

El rasgo 0 indica que el componente no opera en el lexema correspondiente. 


\section{Los rasgos comunes}

Todos los lexemas en este campo presentan algunos rasgos comunes que los asemeja y los hace oponerse a otros campos léxicos.

Estos rasgos comunes son los siguientes:

\section{1. + auxiliares en la elaboración de alimentos.}

Este es el rasgo principal. Todos los utensilios descritos aquí son fundamentales en la preparación de comidas. Sin ellos, difícilmente se podrían manejar los alimentos en su elaboración y cocción.

\section{2. +mango.}

Todos los utensilios que aquí se presentan tienen uno o dos mangos para manejarlos manualmente.

\section{3. - eléctricos.}

Ninguno de ellos es eléctrico.

\section{4. + operación manual.}

Están confeccionados para usarse fácilmente con la mano. Por eso tienen agarradera y son livianos.

\section{5. + activos.}

Todos estos utensilios son operantes, en oposición a los recipientes pasivos, donde reposan los alimentos. Operan activamente en la preparación de los alimentos por su movilidad, por su poco peso y tamaño. 


\section{Cuadro 1}

\section{Rasgos Comunes}

\begin{tabular}{|c|c|c|c|c|}
\hline & Mango & Eléctricos & Manuales & Activos \\
\hline Cuchara & + & - & + & + \\
\hline Cucharón & + & - & + & + \\
\hline Cucharita & + & - & + & + \\
\hline Cucharón sopero & + & - & + & + \\
\hline Molinillo & + & - & + & + \\
\hline Estribo & + & - & + & + \\
\hline Punzón & + & - & + & + \\
\hline Tenedor & + & - & + & + \\
\hline Cuchillo de pan & + & - & + & + \\
\hline Espátula & + & - & + & + \\
\hline Cuchara de madera & + & - & + & + \\
\hline Cucharas de medida & + & - & + & + \\
\hline Rodillo & + & - & + & + \\
\hline Batidor de alambre & + & - & + & + \\
\hline Eslador & + & - & + & + \\
\hline Cortador de queque & + & - & + & + \\
\hline Espátula triangular & + & - & + & + \\
\hline Cernidor & + & - & + & + \\
\hline Punzón para repostería & + & - & + & + \\
\hline Rallador & + & - & + & + \\
\hline Embudo & + & - & + & + \\
\hline Pelador & + & - & + & + \\
\hline Taza de medida & + & - & + & + \\
\hline Paleta & + & - & + & + \\
\hline Cucharón para espagueti & + & - & + & + \\
\hline Cuchillo de picar & + & - & + & + \\
\hline Mazo & + & - & + & + \\
\hline Cortador de pizza & + & - & + & + \\
\hline Partidor de nueces & + & - & + & + \\
\hline
\end{tabular}




\section{Rasgos adicionales}

Estos rasgos permiten oponer unos lexemas con otros para determinar su distribución y su distinción.

Consisten en cuatro variables que son las siguientes:

\subsection{La variable finalidad}

Esta primera variable corresponde al objetivo para el cual se usan los diferentes utensilios. Integra doce valores:

\subsubsection{Cortantes}

Son los instrumentos que se usan para partir, picar, cortar o rebanar los alimentos.

\subsubsection{Aplastantes}

Se usan para aplanar o comprimir un alimento, golpeándolo o aplastándolo.

\subsubsection{Triturantes}

Se usan para quebrar o desmenuzar un alimento compacto.

\subsubsection{Punzantes}

Se usan para punzar o pinchar un alimento.

\subsubsection{Mezcladores}

Se usan para mover dos o más sustancias que se quieren unir.

\subsubsection{Batientes}

Se usan para revolver con fuerza una o más sustancias.

\subsubsection{Servidores}

Se usan para tomar una porción de algún alimento.

\subsubsection{Separadores}

Se usan para sacar o apartar una materia de otra. 


\subsubsection{Afinadores}

Se usan para hacer fina una sustancia, eliminándole la materia gruesa.

\subsubsection{Dosificadores}

Se usan para medir la cantidad exacta de cualquier sustancia.

\subsubsection{Trasvasadores}

Se usan para cambiar una sustancia (sobre todo líquida) de un envase a otro.

\subsubsection{Escarbadores}

Se usan para despegar los restos de una sustancia que quedan en el fondo y a los lados de un recipiente.

\subsection{La variable forma}

La segunda variable corresponde a la estructura o configuración de los utensilios. Presenta ocho valores que son:

\subsubsection{Cóncavos}

Tienen la superficie más hundida en el centro que a los lados.

\subsubsection{Planos}

$\mathrm{Su}$ superficie es lisa y llana.

\subsubsection{Redondos}

Son utensilios de figura circular.

\subsubsection{Ovalados.}

Tienen forma de huevo; es decir son curvos y oblongos.

\subsubsection{Ahuecados}

Tienen aberturas largas en su superficie. 


\subsubsection{Puntiagudos}

Son los utensilios cuya extensión termina en una punta aguda.

\subsubsection{Filo liso}

Tienen el filo parejo, sin asperezas ni ondulaciones.

\subsubsection{Con salientes}

Tienen una forma irregular en su superficie; de ella salen varios resaltos.

\subsection{Variable tamaño}

La variable tamaño señala las proporciones de los utensilios en una progresión de mayor a menor. Esta variable presenta algunas casillas vacías, porque en muchos casos, el tamaño de los utensilios no representa un rasgo que les permita oponerse a otros. Muestra tres valores:

\subsubsection{Neutro}

Es el tamaño regular, que representa el punto medio en la progresión.

\subsubsection{Grande}

Es un tamaño mayor que el regular. Representa el punto mayor en la progresión.

\subsubsection{Pequeño}

Es un tamaño menor que el regular. Representa el punto menor en la progresión.

\subsection{Variable material}

Esta variable se refiere a la materia con la que están fabricados los instrumentos. Muestra un valor:

\subsubsection{El valor positivo es + madera}

El operador - (negativo) indica que el utensilio está hecho de cualquier otro material, excepto de madera.

\section{Definición componencial}

Con base en las oposiciones establecidas, a continuación se suministra una definición componencial de cada uno de los lexemas. Los componentes comunes se presentan en todos los 
lexemas: + mango, - eléctricos, + operación manual, + activos. Estos se indicarán con las siglas R.C. Los restantes corresponden a los componentes adicionales (cfr. Margery: 1984: 26-31). Al lado de cada definición se colocará un número, el cual corresponde a la ilustración respectiva.

4.1. Cuchara: R.C. [+ mezclador, + servidor, \pm escarbar $]$, [+ cóncavo, + ovalado], [+ tamaño neutro], [-madera].

4.2. Cucharón: R.C. [+ mezclador, + servidor], [+ cóncavo, + ovalado], [+ tamaño grande].

4.3. Cucharita: R.C. [+ mezclador, + servidor], [+ cóncavo, + ovalado], [+ tamaño pequeño].

4.4. Cucharón sopero: R.C. [+ servidor], [+ cóncavo, + ovalado], [+ tamaño grande].

4.5. Molinillo: R.C. [+ batiente], [+ ovalado], [+ de madera].

4.6. Estribo: R.C. [+ aplastante, + triturante], [ \pm cóncavo, \pm plano, + ahuecado].

4.7. Punzón: R.C. [+ triturante, + punzante], [+ puntiagudo], [ \pm grande , \pm neutro].

4.8. Tenedor: R.C. [+ punzante, + batiente, + servidor], [+ cóncavo, + ahuecado, + puntiagudo, + con salientes].

4.9. Cuchillo de pan: R.C. [+ cortante], [+ plano, \pm puntiagudo, + con salientes], [+ grande].

4.10. Espátula: R.C. [+ servidor, +separador], [+ plano, \pm redonda, + ahuecada].

4.11. Cuchara de madera: R.C. [+ mezclador, + servidor], [+ cóncavo], [ \pm grande, \pm neutra], [+ de madera].

4.12. Cucharas de medida: R.C. [+ dosificadoras], [+ cóncavas, \pm redondas, \pm ovaladas], [ \pm neutras, \pm pequeñas].

4.13. Rodillo: R.C. [+ aplastante], [+ redondo], [ \pm de madera].

4.14. Batidor de alambre: R.C. [+ batiente], [+ ovalado, + ahuecado].

4.15. Colador: R.C. [+ separador, + afinador], [+ cóncavo, + ahuecado].

4.16. Cucharón perforado: R.C [+ mezclador, + servidor, + separador], [+ cóncavo, + ovalado, +ahuecado], [+ grande].

4.17. Cortador de queque: R.C. [+ cortante, \pm servidor], [+ plano, \pm puntiagudo, + con salientes].

4.18. Espátula triangular: R.C. [+ cortador, + servidor], [+plano, + puntiagudo].

4.19. Cernidor: R.C. [+ separador, + afinador], [+ plano, + ahuecado].

4.20. Punzón para repostería: R.C. [+ punzante], [+ puntiagudo], [+ pequeño].

4.21. Rallador: R.C. [+ cortante, + afinador], [+ plano, + con salientes, + filo liso].

4.22. Embudo: R.C. [+ trasvasador], [+ cóncavo, + redondo].

4.23. Pelador: R.C. [+ cortante], [+ cóncavo, + ahuecado, + filo liso].

4.24. Taza de medida: R.C. [+ dosificador], [+ plano, + redondo].

4.25. Paleta: R.C. [+ dosificador], [+ plano, + redondo].

4.26. Cucharón para espagueti: R.C. [+ servidor], [+ cóncavo, + ovalado, + ahuecado, + con salientes].

4.27. Cuchillo para picar: R.C. [+ cortante], [+ plano, + puntiagudo, + filo liso], [ \pm neutro, \pm pequeño].

4.28. Mazo: R.C. [+ aplastante], [+ con salientes], [ \pm de madera].

4.29. Cortador de pizza: R.C. [+ cortante], [+ plano, + redondo, + filo liso].

4.30. Partidor de nueces: R.C. [+ aplastante, + triturante], [+ cóncavo, + con salientes]. 


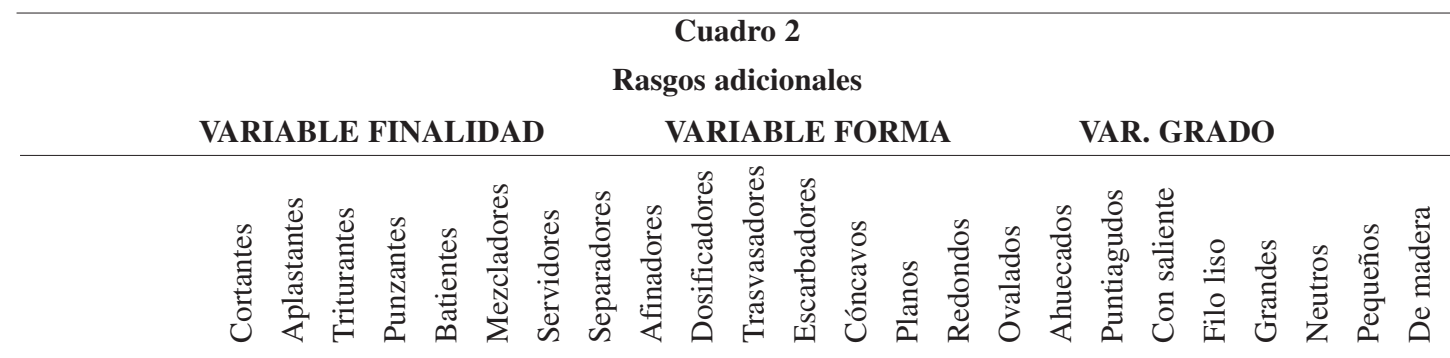

Cuchara

Cucharón

Cucharita

Cucharón

sopero

Molinillo

Estribo

Punzón

Tenedor

Cuchillo de

pan

Espátula

Cucharas de

medida

Cuchara de

madera

Rodillo

Batidor de

alambre

Colador

Cucharón

perforado

Cortador de

queque

Espátula

triangular

Cernidor

Punzón para

repostería

Rallador

Embudo

Pelador

Taza de

medida

Paleta

Cucharón para

espagueti

Cuchillo

para picar

Mazo

Cortador

de pizza

Partidor

de nueces 


\section{Conclusiones}

Una vez realizado el análisis componencial, con base en el campo léxico de los utensilios de cocina activos, manuales, no eléctricos, con mango, es importante señalar que las definiciones que resultan con la aplicación de este método son un poco parciales, debido a que se aísla una parte del léxico y, a partir de ella, se establecen cierto tipo de relaciones que podrían cambiar si se tomaran otras parcelas del léxico. Una restricción de este método es que no permite tomar en cuenta algunos lexemas que se alejan un poco de las variables generales que se establecen. Por ejemplo, en este caso, se tuvieron que eliminar utensilios como el mortero y la pinza, ya que resultaba muy difícil ajustarlos a los componentes definidos.

Otra limitación concuerda con lo que plantea Lyons (1981:88):

... si siempre seleccionamos aquellos componentes que se pueden identificar en el mayor número de lexemas acabaremos con frecuencia en un análisis de los lexemas particulares menos económico y sistematizado de lo que haríamos si analizáramos cada lexema en sus propios términos.

Esta puede ser una limitación más del investigador que del método propiamente; por tanto, es importante que el análisis sea económico al establecer los componentes. Se debe recurrir a los que sean necesarios y suficientes para oponer unos lexemas con otros, para que no se lleguen a determinar componentes redundantes e innecesarios.

Por otra parte, el análisis componencial es un método que permite darle un carácter más regular y sistemático al problema del significado léxico, al organizar un paradigma y atribuir a los lexemas unos rasgos semánticos comunes, y otros rasgos semánticos que los oponen.

De acuerdo con sus relaciones paradigmáticas, es posible plantear las relaciones de sentido de dichos lexemas.

Al realizar este trabajo, se pudo llegar a las siguientes conclusiones:

\subsection{Se atribuyó un significado prototípico a cada uno de los lexemas, porque sólo de esa manera se pueden formular unidades discretas.}

Es verdad que, por ejemplo un tenedor, además de punzar, batir y servir, podría también aplastar, cortar, escarbar, separar, etc., pero todos esos usos no son pertenecientes en lo que se refiere a la finalidad prototípica de ese utensilio. Existen otros que sirven típicamente para esas otras funciones.

\subsection{Se establecieron las siguientes relaciones de sentido:}

5.2.1. Sinonimia: En todas las encuestas realizadas, se definieron el punzón y el picahielo con los mismos componentes: [+ punzante], [+ puntiagudo], [ \pm grande, \pm neutral].

Algunos informantes dieron otra relación de sinonimia, entre el cortador de queque y la espátula triangular. Les atribuían a los dos instrumentos las cualidades del último: [+servidor, + cortador], [+plano, +puntiagudo]. 
5.2.2. Antonimia: Se estableció una oposición gradual entre los lexemas cuchara, cucharón y cucharita, los cuales se diferencian por la variable de grado: el cucharón es + grande, la cuchara es + neutra y la cucharita es + pequeña.

5.2.3. Hiponimia: En muchos casos, los informantes incluyeron algunos utensilios como el cucharón, cucharón perforado y espátula dentro del lexema cuchara; incluso, a todos estos los llaman cucharas. Este lexema posee un uso y un significado más generales.

5.2.4. Los demás lexemas están en relación equipolente unos con otros.

5.3. Este paradigma se puede incluir dentro de los campos seriales no ordinales, ya que constituye una serie abierta, a la que se puede añadir nuevos lexemas indefinidamente.

\section{Bibliografía}

Bierwisch, M. 1970. "Semantics". En: Lyon, J. (ed.).

Coseriu, E. 1977. Principios de semántica estructural. Madrid: Editorial Gredos.

Geckeler, H.1976. Semántica estructural y teoría del campo léxico. Madrid: Editorial Gredos.

Lehrer, A. 1974. Semantic fields and lexical structure. London: North-Holland Publishing Company.

Lyons, J. 1981. Lenguaje, significado y contexto. Barcelona: Paidós Comunicación. 1970. Nuevos horizontes de la lingüística. Madrid: Alianza Editorial. 1970. Semantics. Cambridge University Press.

Jara, C. 1986. El campo léxico de la vivienda en el bribri de Coroma. Tesis de maestría. Universidad de Costa Rica. 
6. Apéndice

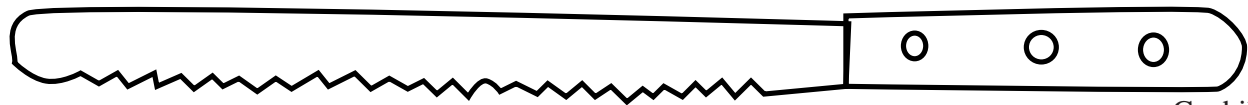

Cuchillo para pan
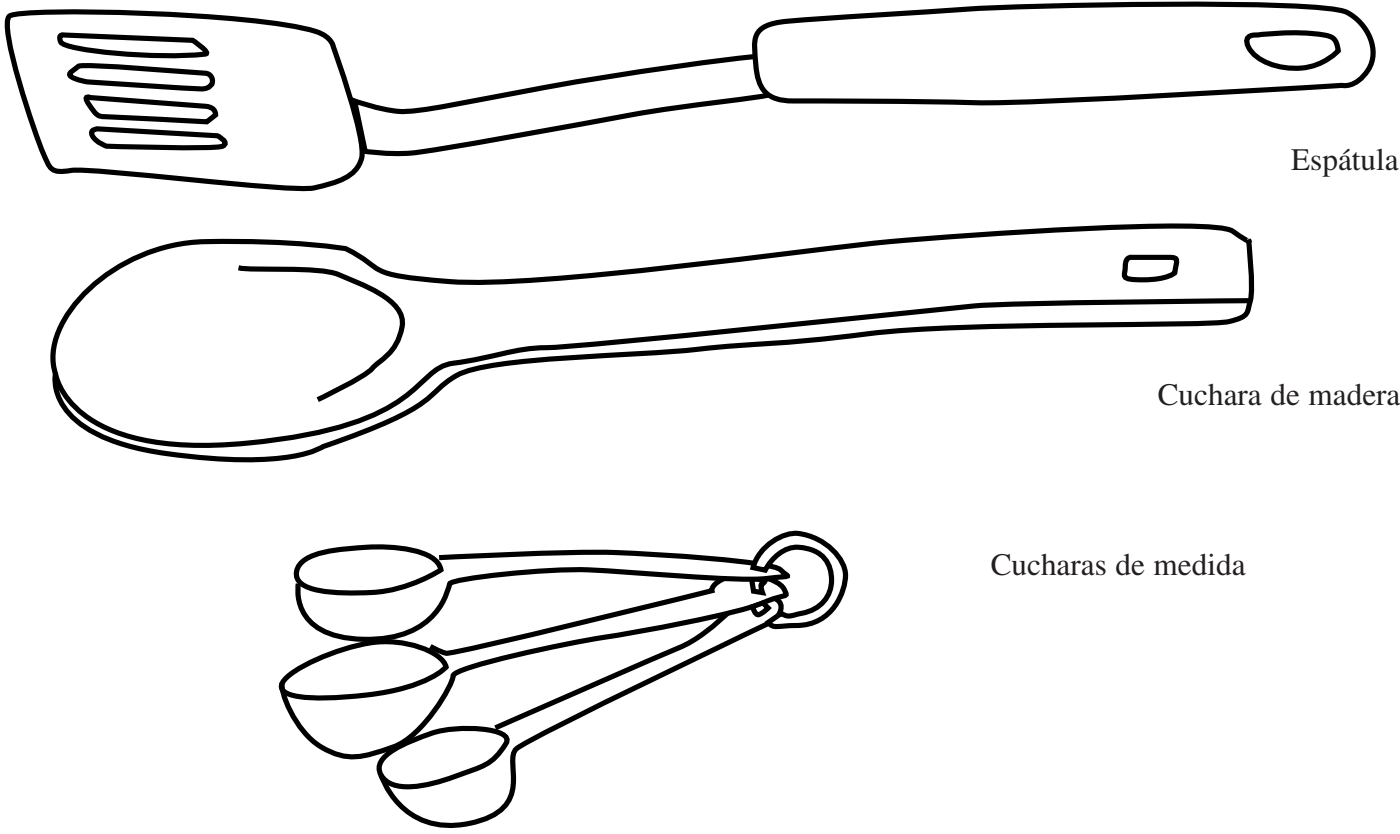

Cucharas de medida
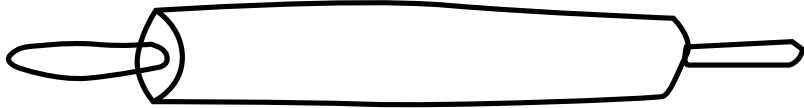

Rodillo
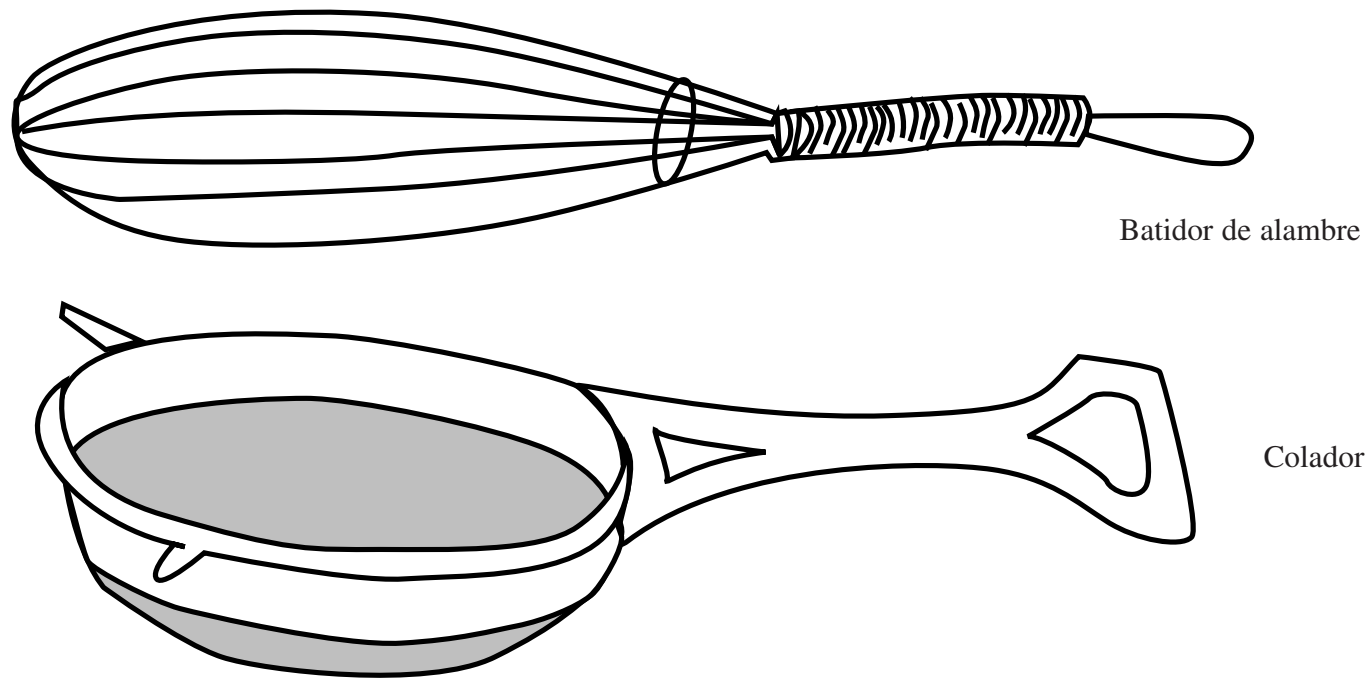

Colador 

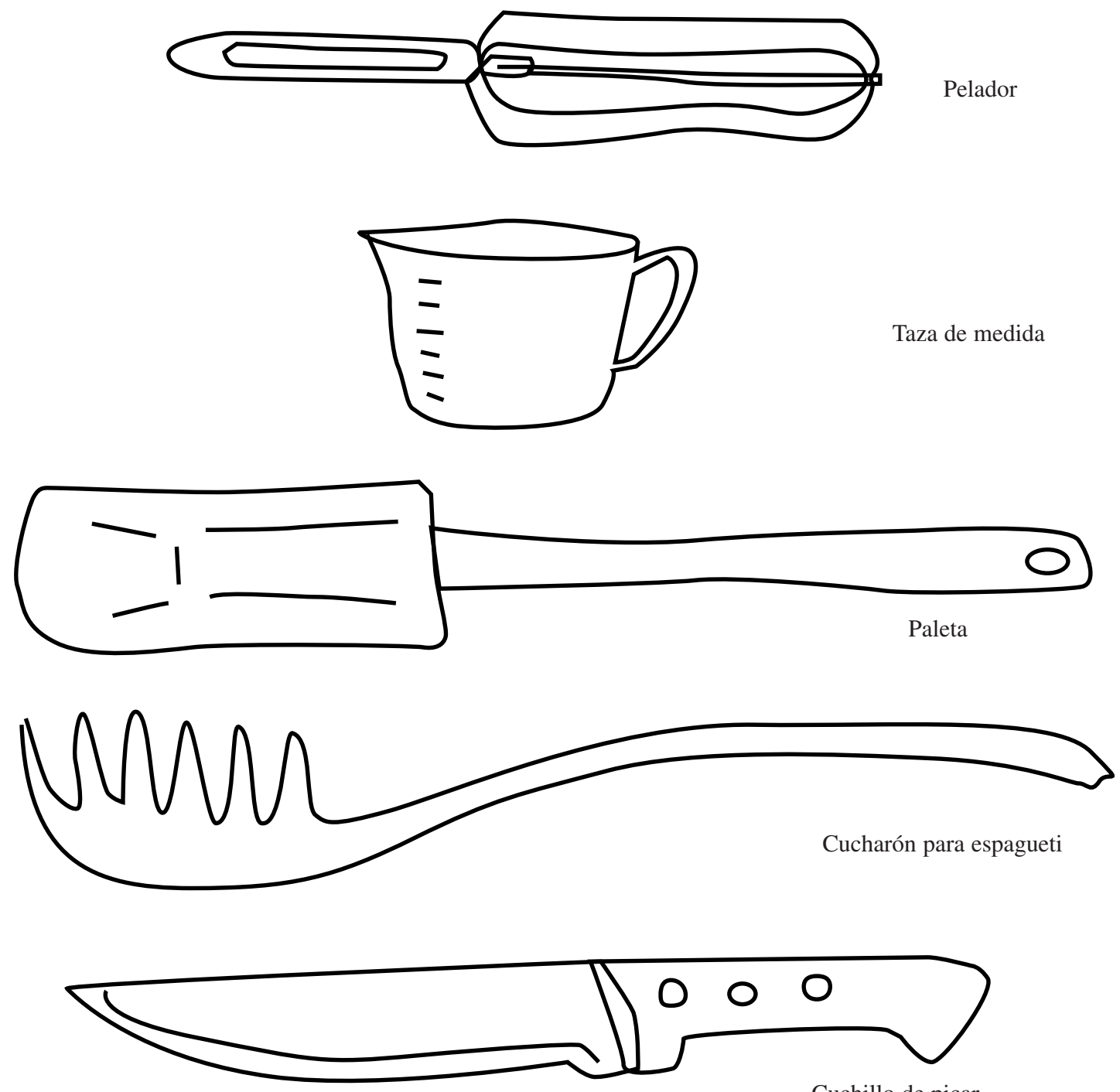

Cuchillo de picar

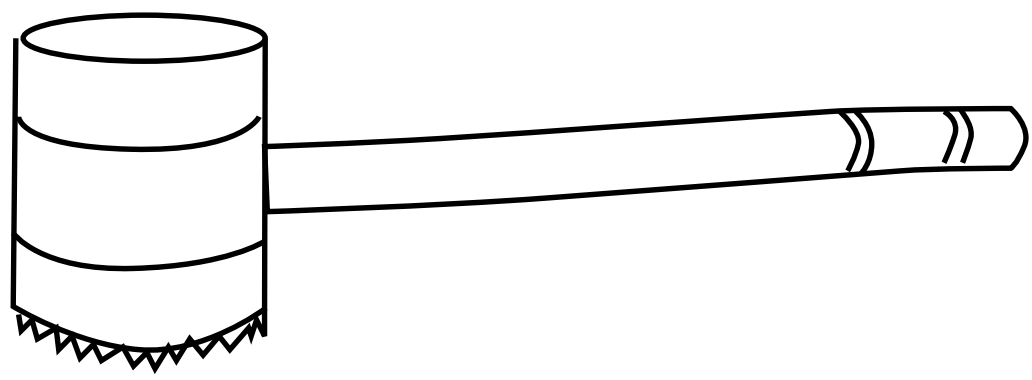



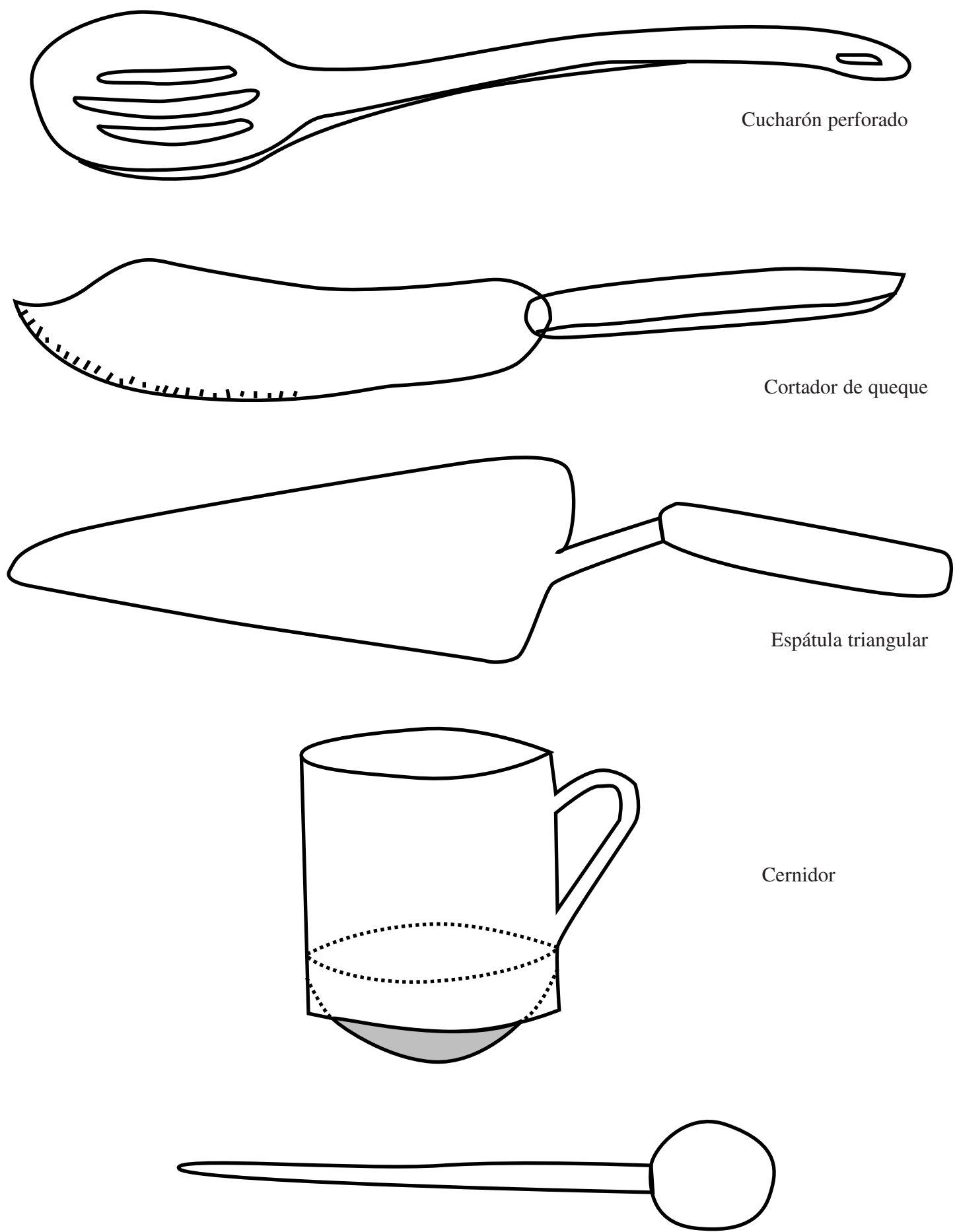

Punzón para respostería 


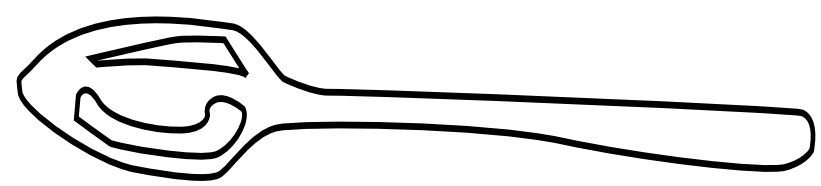

Cuchara

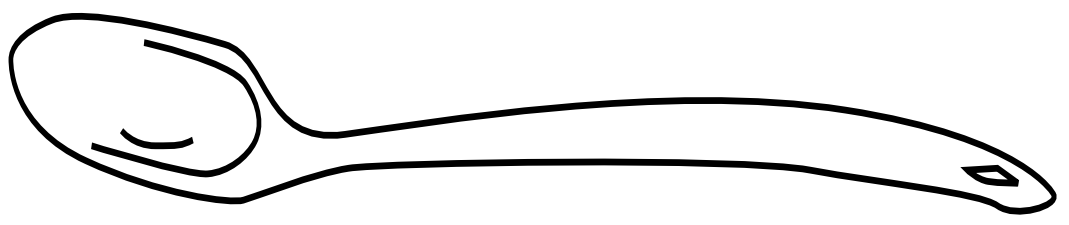

Cucharón

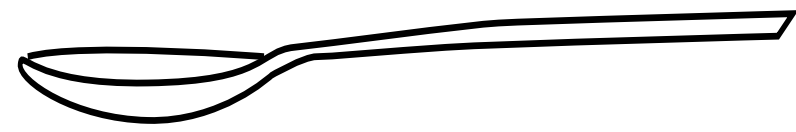

Cucharita

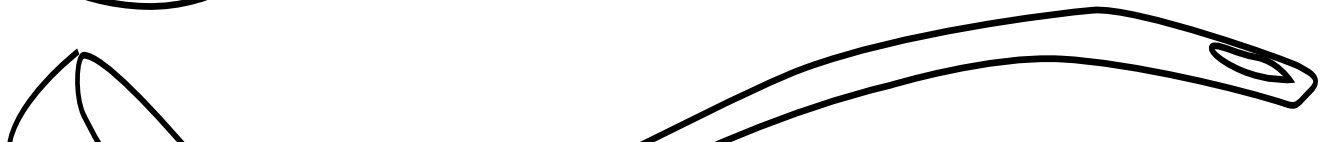

Cucharón sopero

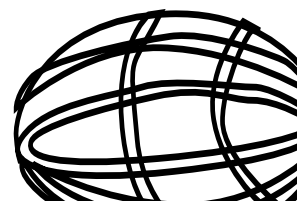

पाषाप

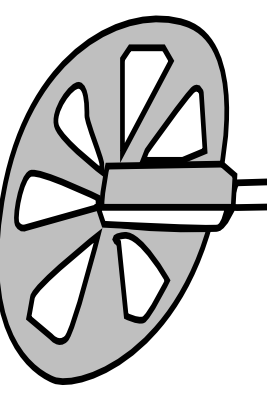

Molinillo

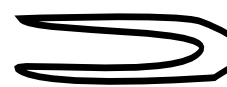

Punzón

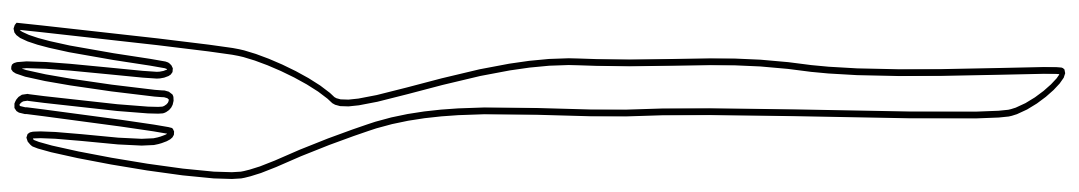



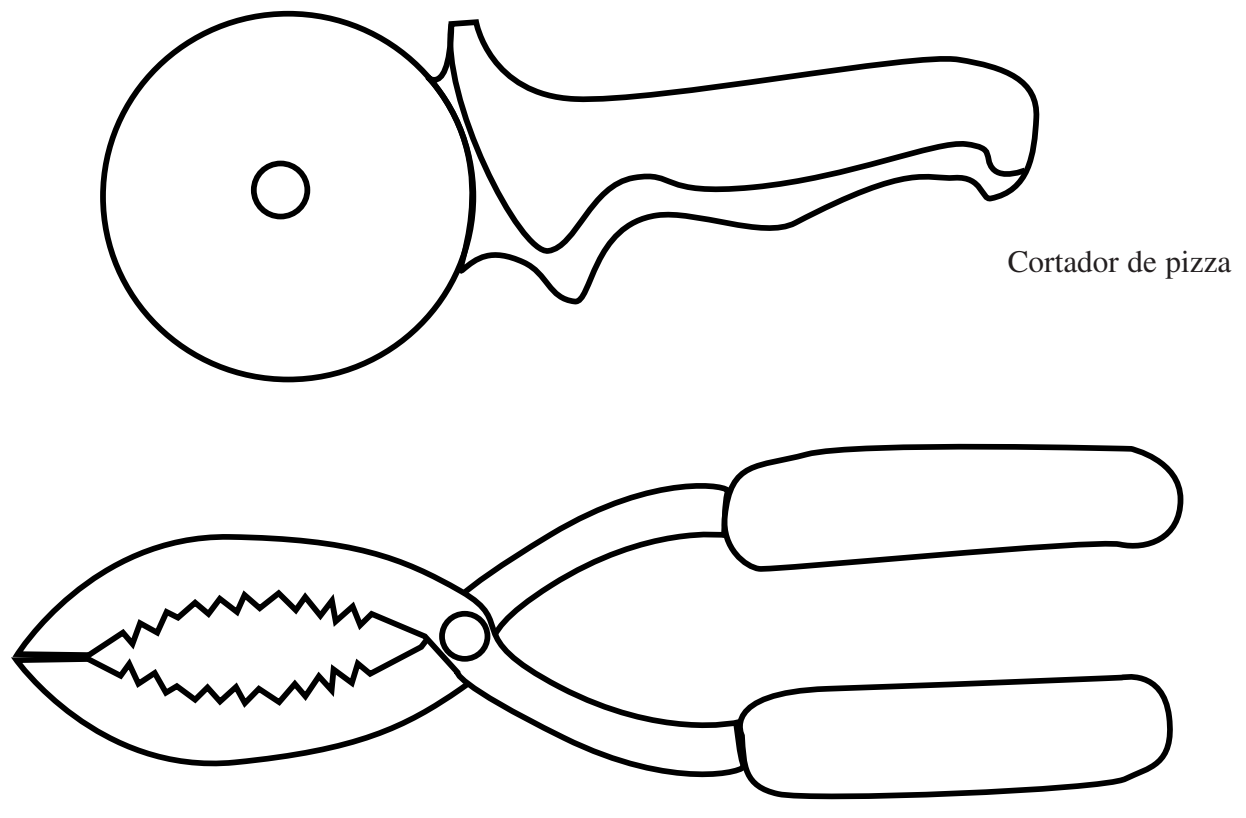

Partidor de nueces

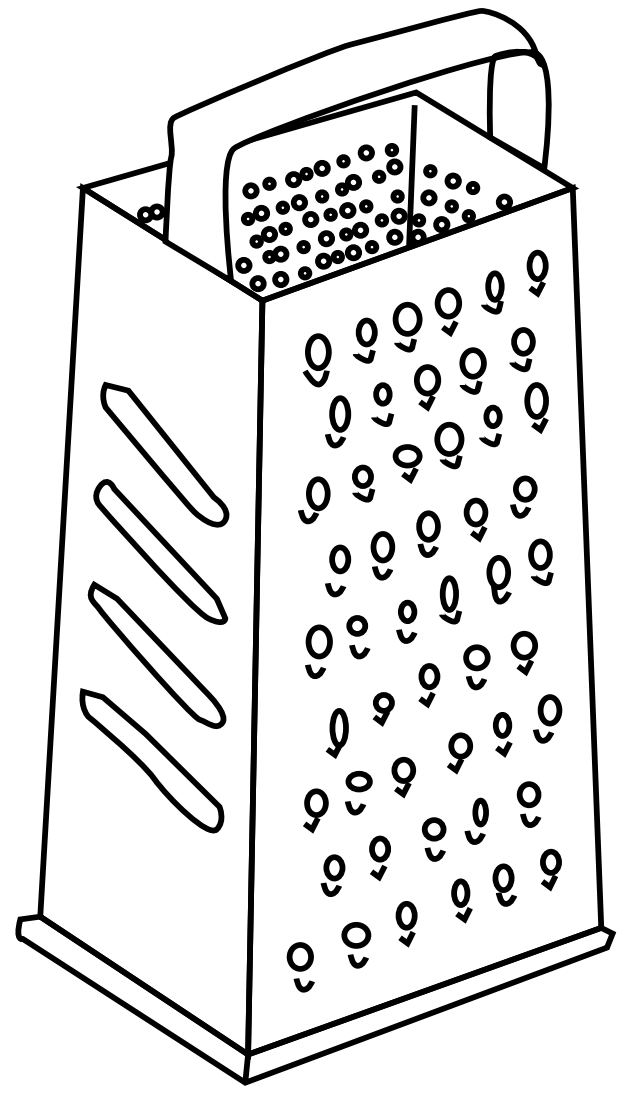

Rallador

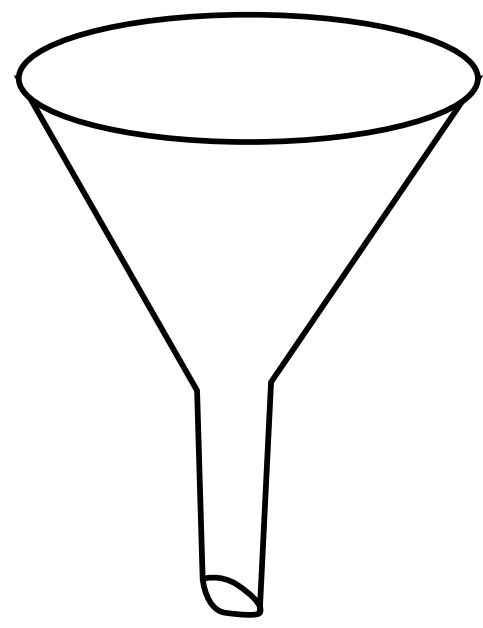

Embudo 